\title{
A IMPORTÂNCIA DA EMPATIA NO PROCESSO DE COMUNICAÇÃO INSTITUCIONAL DE UM HOSPITAL PÚBLICO DE ENSINO DO ESTADO DE SÃO PAULO
}

Caroline Maiolini Mizael ${ }^{1}$ | Ligia Mayumi Abe ${ }^{2}$ | Rosemeire Keiko Hangai ${ }^{3}$ | Marisa Riscalla Madi ${ }^{4}$ | Ivisen Teixeira Lourenço ${ }^{5}$

\section{INTRODUÇÃO}

Design Thinking é uma abordagem inovadora centrada em descobrir soluções mais aderentes às reais necessidades das pessoas. Possui a capacidade de utilizar a empatia, de forma a colocar as pessoas no centro do desenvolvimento do projeto. Para isso, é preciso se aprofundar sobre os problemas enfrentados pela instituição e através do processo de empatia, identificar suas dificuldades e ganhos. Com a intenção de aplicar a empatia como uma abordagem para resolução de problemas gerenciais do hospital, a pesquisa foi proposta com foco na comunicação institucional.

\section{OBJETIVO}

Identificar o problema no processo de comunicação institucional aplicando a empatia como abordagem.

\section{METODOLOGIA}

Foi desenvolvida a etapa de imersão do Design Thinking. As ferramentas utilizadas foram: Mapa de Empatia e Persona Canvas.

\section{ETAPAS DO DESIGN THINKING}

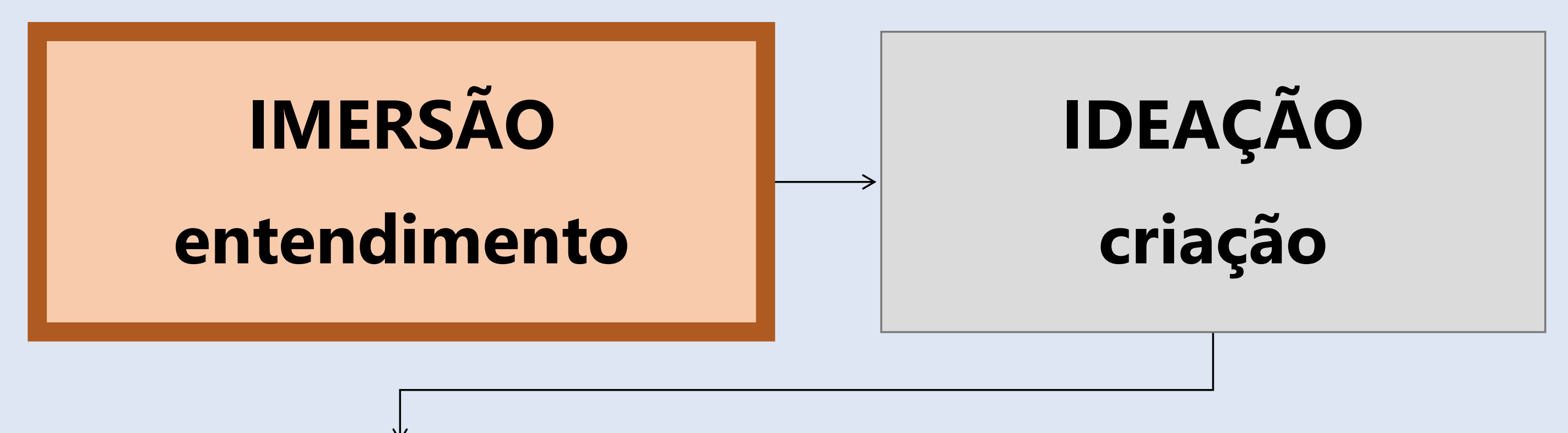

\section{PROTOTIPAÇÃO}

teste

\section{DESENVOLVIMENTO}

aplicação

\footnotetext{
12 Aprimorandas do Programa de Estudos Avançados em Administração Hospitalar e de Sistemas de Saúde (PROAHSA).

${ }^{3}$ Coordenadora de ensino do PROAHSA.

4 Diretora Executiva do Instituto de Radiologia do Hospital das Clínicas da Faculdade de Medicina da Universidade de São Paulo (InRad).

${ }^{5}$ Gerente de Inovação e Marketing do InRad.
}

\section{RESULTADOS E DISCUSSÃO}

ETAPA DE IMERSÃO

Acompanhamento de um dia de trabalho e entrevista com os colaboradores.

\section{MAPA DA EMPATIA}

Visualização do que os colaboradores veem, falam, escutam, fazem, pensam e sentem sobre a comunicação institucional.

\section{PERSONA CANVAS}

Criação de um personagem fictício para representar o colaborador: Técnica de enfermagem de 45 anos, trabalha na instituição há 15 anos, além de trabalhar em outro hospital. É introvertida, passiva e racional. Usa frequentemente o celular para redes sociais.

Foram apontadas 6 dificuldades e 6 ganhos sobre a comunicação institucional:

\section{DORES}

Muitos e-mails.

E-mails que não são da área/setor.

Informações desinteressantes e não atrativas.

Comunicação verbal ineficaz.

Poucas reuniões sobre assuntos institucionais.

\section{GANHOS}

Participar das discussões sobre estratégias. Informações individualizadas e personalizadas.

Maior interação pessoal. Se sentir mais valorizado. Informações rastreadas. Informações rápidas, simples e objetivas.

\section{CONCLUSÃO}

As ferramentas aplicadas possibilitaram 0 desenvolvimento de empatia com os colaboradores e, dessa forma, a proposição de melhorias que atinjam as principais dificuldades e ganhos sobre o processo de comunicação. É uma abordagem inovadora, ágil e econômica.

\section{REFERÊNCIAS}

MASSARI, V. L.; VIDAL, A. Gestão ágil de produtos com Agile Think Business Framework: Guia para certificação EXIN Agile Scrum Product Owner. Edição digital: Brasport, 2018.

VIANNA, M.; VIANNA, Y.; ADLER, I. K.; LUCENA, B.; RUSSO, B. Design Thinking: Inovação em negócios. Rio de Janeiro: MJV Press, 2012. 